\title{
Perforación de colon sigmoides por migración de dispositivo intrauterino
}

Sigmoid colon perforation by intrauterine device migration

David Daroch M. ${ }^{1,2}$, Daniella Espínola M. ${ }^{1,2}$ y Aldo Cuneo Z. ${ }^{1}$

'Departamento de Cirugía Clínica Alemana de Santiago. Santiago, Chile.

2Departamento de Cirugí Hospital Padre Hurtado. Universidad del Desarrollo. Santiago, Chile.

Recibido el 19 de junio de 2017 y aceptado par publicación el 29 de junio de

2017

Correspondencia a: Dr. David Daroch M dadaroch@gmail.com
Mujer de 53 años con antecedentes de colocación de DIU hace 30 años, con múltiples consultas en servicio de urgencia por dolor lumbar bajo intenso de 5 días de evolución que no responde a manejo analgésico.

Radiografía lumbar: normal. Resonancia magnética y tomografía axial computarizada de columna lumbar: fístula de colon sigmoides a la región presacra determinada por dispositivo intrauterino (DIU) migrado con elementos sugerentes de osteomielitis de S3 (Figuras 1, 2 y 3).

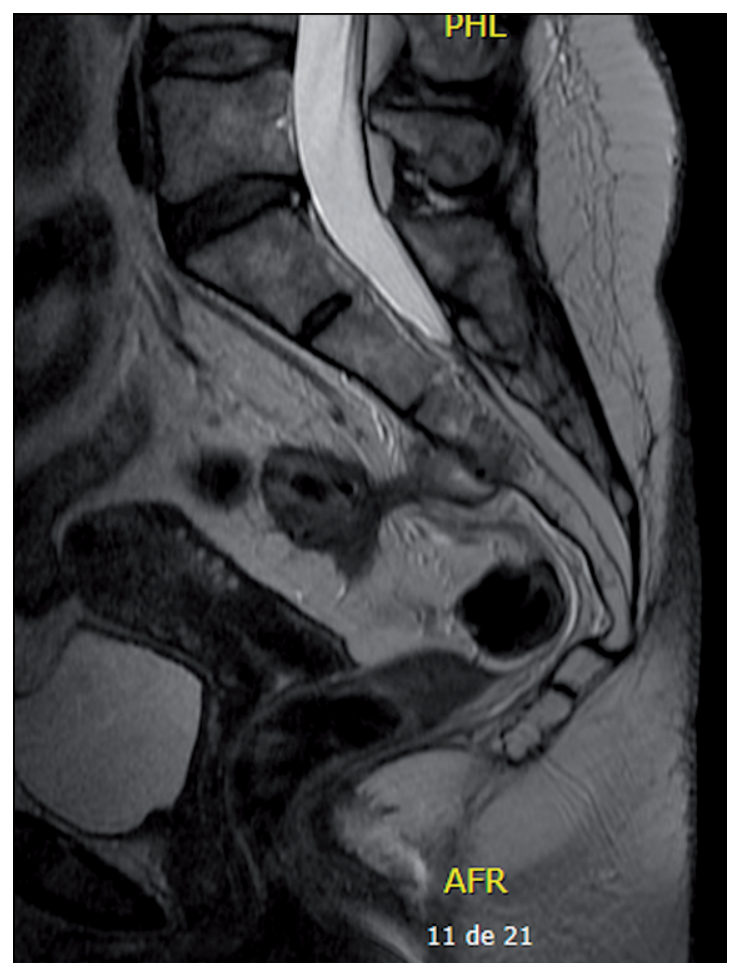

Figura 1. RNM. Corte Sagital. T1. Fístula de colon sigmoides a la región presacra.

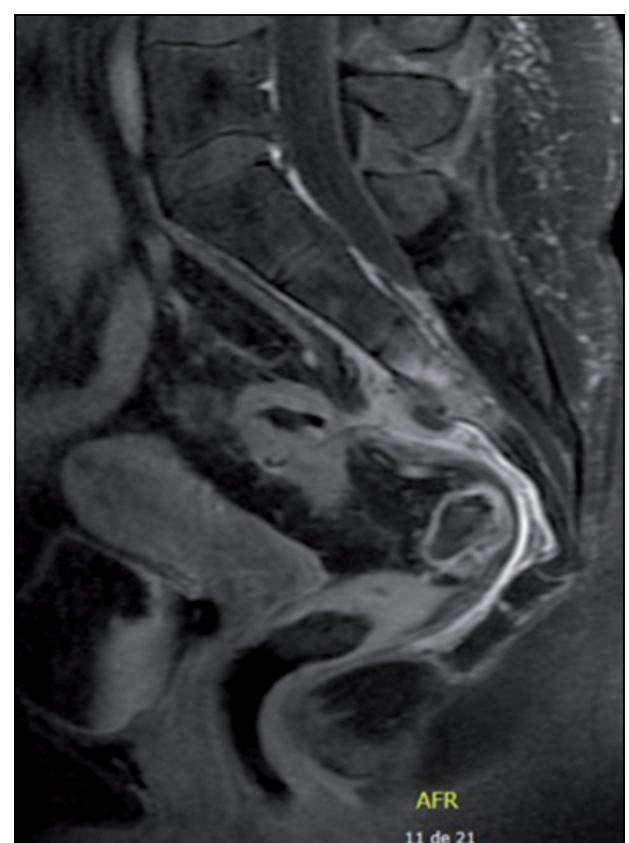

Figura 2. RNM. Corte Sagital. T2. Fístula de colon sigmoides a la región presacra.

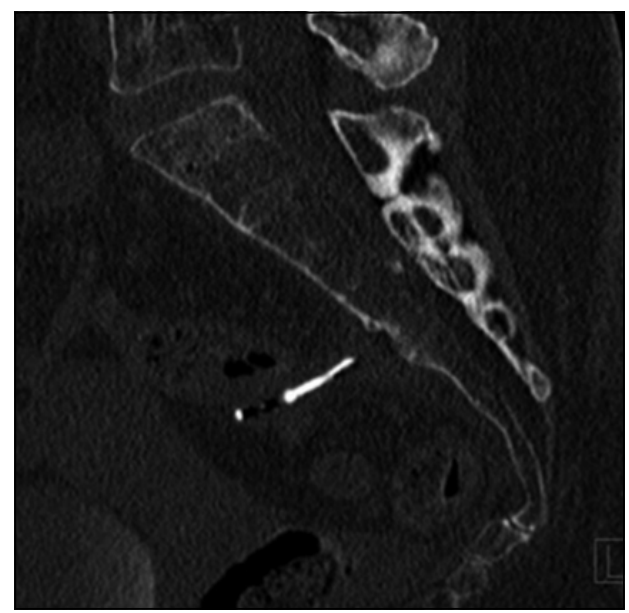

Figura 3. TC. Corte Sagital. Fístula de colon sigmoides a la región presacra determinada por DIU. 
Se decide exploración quirúrgica: colón sigmoides fijo a región sacra con 3 perforaciones causadas por DIU (Figura 4). Se realiza sigmoidectomía con anastomosis mecánica colorrectal termino-terminal y curetaje de la zona presacra. Biopsia sin evidencia de malignidad.

La perforación uterina y migración del DIU es la complicación más grave del uso de este dispositivo. Se estiman 1-2 casos por 1.000 inserciones de DIU ${ }^{1}$, de los cuales el $15 \%$ afecta un órgano vecino y el $40 \%$ de estos sería al colon sigmoides ${ }^{2}$.

La indicación actual es el retiro mediante cirugía debido a que podría causar síntomas y complicaciones tales como perforaciones, fístulas, adherencias, infertilidad. Cuando ocurre una complicación la indicación absoluta es la cirugía. Debido al gran proceso adherencial e inflamatorio, el manejo incluye resección del segmento intestinal comprometido ${ }^{3}$.

\section{Responsabilidades éticas}

Protección de personas y animales. Los autores declaran que para esta investigación no se han realizado experimentos en seres humanos ni en animales.

Confidencialidad de los datos. Los autores declaran que han seguido los protocolos de su centro de trabajo sobre la publicación de datos de pacientes.

Derecho a la privacidad y consentimiento informado. Los autores declaran que en este artículo no aparecen datos de pacientes.

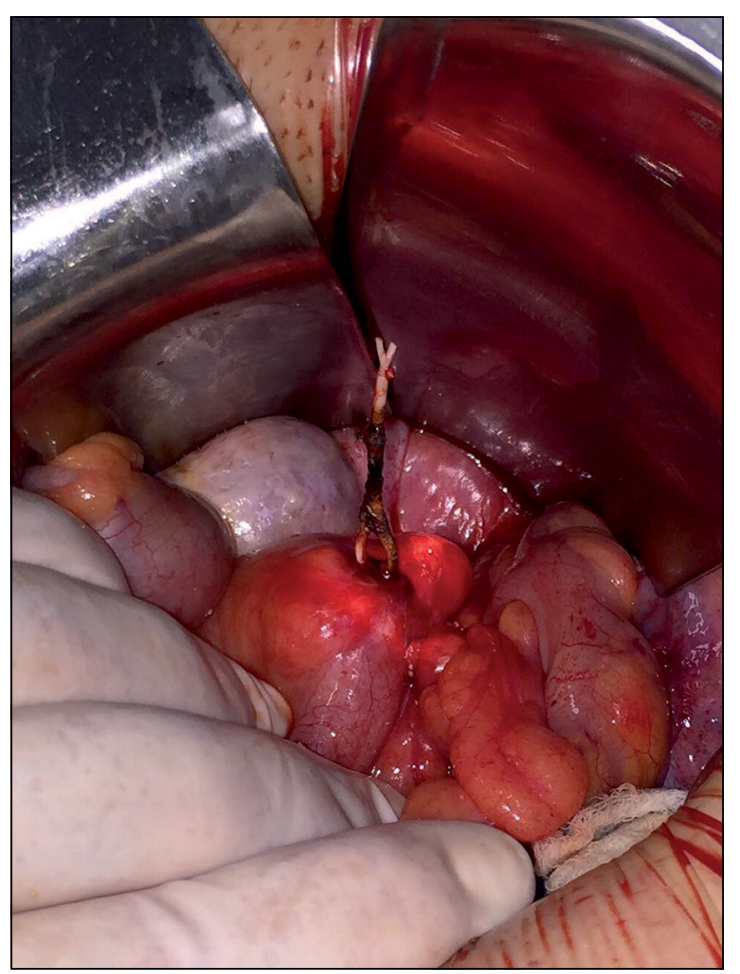

Figura 4. Cirugía. Perforación de colón sigmoides determinada por DIU.

\section{Financiación}

Los autores declaran no haber recibido ninguna financiación para la realización de este trabajo.

\section{Conflicto de intereses}

Los autores declaran no tener ningún conflicto de intereses.

\section{Bibliografía}

1. Gill RS, Mok D, Hudson M, Shi X, Birch DW, Karmali S. Laparoscopic removal of an intra-abdominal intrauterine device: case and systematic review. Contraception
2012;85:15-8.

2. Toprak E, Göktürk HS, Tolu A. A new technique for the removal of a transmigrated intrauterine device with rectum penetration. Turk J Gastroenterol. $2015 ; 26: 82-4$
3. Adiyeke M, Sanci M, Karaca I, Gökçü M, Töz E, Ocal E. Surgical management of intrauterine devices migrated towards intra-abdominal structures: 20-year experience of a tertiary center. Clin Exp Obstet Gynecol. 2015;42:358-60. 